\title{
CONSUMO DE PROTEÍNA DO SORO DO LEITE ENTRE ESTUDANTES UNIVERSITÁRIOS DE PORTO ALEGRE, RS
}

CONSUMPTION OF WHEY PROTEIN AMONG UNIVERSITY STUDENTS OF PORTO ALEGRE, RS

CONSUMO DE PROTEÍNA DEL SUERO DE LECHE ENTRE ESTUDIANTES UNIVERSITARIOS DE PORTO ALEGRE, RS

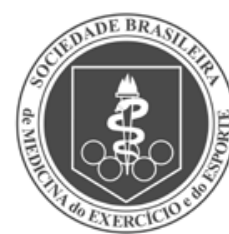

Artigo Original

Original ARticle

Artículo Original
Jéssica de Oliveira Saudades (Nutricionista)

Vanessa Ramos Kirsten² (Docente do Curso de Nutrição)

Viviani Ruffo de Oliveira ${ }^{3}$

(Docente do Curso de Nutrição)

1. Universidade Federal do Rio Grande do Sul (UFRGS), Porto Alegre, RS, Brasil.

2. Universidade Federal de Santa Maria (UFSM), Campus Palmeira das Missões, RS, Brasil.

3. Universidade Federal do Rio Grande do Sul (UFRGS), Faculdade de Medicina (FAMED), Porto Alegre, RS, Brasil.

\section{Correspondência: \\ Viviani Ruffo de Oliveira Universidade Federal do Rio Grande do Sul (UFRGS). Faculdade de Medicina - Departamento de Nutrição. Rua Ramiro Barcelos 2400, Porto Alegre, RS, Brasil. 90035-000. viviani.ruffo@ufrgs.br}

\section{RESUMO}

Introdução: A proteína do soro do leite é uma das proteínas de maior valor biológico, por seu alto teor de aminoácidos. Em vista disso, a população tem consumo elevado do suplemento alimentar Whey Protein e esse uso exacerbado torna-se preocupante. Objetivo: Avaliar o perfil do consumo de Whey Protein (WP) bem como verificar como é utilizado, quais os tipos consumidos e se esse consumo está associado à prática de atividade física, além de se há alguma recomendação profissional. Métodos: A população analisada foi de alunos da Universidade Federal do Rio Grande do Sul, em Porto Alegre, matriculados nos cursos de graduação das áreas Biológicas, Naturais e Agrárias. As áreas contempladas foram selecionadas mediante sorteio e no total foram 11 cursos pertencentes a essas áreas que aceitaram participar do estudo. $O$ instrumento de pesquisa utilizado para o objetivo proposto foi um questionário composto de 15 questões, sendo quatro questões de múltipla escolha. Resultados: Participaram do estudo 133 indivíduos com idade entre 18 e 28 anos (58,6\% homens e $41,3 \%$ mulheres). Com relação à renda, 71,4\% dos participantes ganham em média até três salários mínimos. 0 principal motivo do consumo de proteína do soro do leite foi a hipertrofia muscular (83,5\%). O uso do suplemento Whey Protein foi indicado, em 62,4\% dos casos, por amigos, vendedores ou por iniciativa própria. Conclusão: Fica evidente neste estudo, que a busca de melhor desempenho físico associado a padrões estéticos parece estar impulsionando o uso de Whey Protein, contudo, é preciso também conhecer o risco do uso exacerbado, principalmente quando não há acompanhamento de profissional qualificado nem há recomendações sobre quantidade, tipo e fracionamento do suplemento.

Descritores: proteínas; suplementos nutricionais; consumo de alimentos.

\section{ABSTRACT}

Introduction: The whey protein is one of the proteins of higher biological value because of its high content of amino acids. Therefore, the population has a high consumption of the dietary supplement Whey Protein and this exacerbated use becomes worrisome. Objective: To evaluate the profile of Whey Protein (WP) intake as well as verify how it is used, what types are consumed and whether this consumption is associated with physical activity and if there is any professional recommendation. Methods: The analyzed population was of students in the Federal University of Rio Grande do Sul in Porto Alegre, enrolled in undergraduate courses of Biological, Natural and Agricultural areas. The areas considered were selected by raffle and in total there were 11 courses belonging to these areas that agreed to participate in the study. The research tool used to the proposed objective was a questionnaire composed of 15 questions, four of which were multiple-choice questions. Results: A total 133 individuals aged 18 to 28 years (58.6\% males and $41.3 \%$ females) participated in the study. As for income, $71.4 \%$ of participants earn on average up to three minimum wages. The main reason for consumption of Whey Protein was muscle hypertrophy (83.5\%). The use of Whey Protein supplement was indicated in $62.4 \%$ of cases by friends, sellers, or own initiative. Conclusion: It is evident in the study that the search for better physical performance associated with aesthetic standards seems to be boosting the use of Whey Protein, however it is also necessary to know the risk of excessive use, especially when there is no qualified professional follow-up nor recommendations on quantity, type, and fractionation of the supplement.

Keywords: proteins; dietary supplements; food consumption.

\section{RESUMEN}

Introducción: La proteína del suero de leche es una de las proteínas de mayor valor biológico, por su alto contenido de aminoácidos. En vista de esto, la populación tiene un consumo elevado del suplemento alimenticio Whey Protein y este uso exacerbado se vuelve preocupante. Objetivo: Evaluar el perfil del consumo de Whey Protein (WP) así como verificar cómo se utiliza, qué tipos son consumidos y si ese consumo está asociado a la práctica de actividad física, además de si existe alguna recomendación profesional. Métodos: La población analizada fue de alumnos de la Universidad Federal de Rio Grande do Sul, en Porto Alegre, matriculados en los cursos de graduación de las áreas Biológicas, Naturales y Agrarias. Las áreas contempladas fueron seleccionadas mediante sorteo y en total fueron 11 cursos pertenecientes a esas áreas que aceptaron participar del estudio. El instrumento de investigación utilizado para el objetivo propuesto fue un cuestionario compuesto de 15 preguntas, siendo cuatro cuestiones de múltiple elección. Resultados: Participaron del estudio 133 individuos con edad entre 18 y 28 años (58,6\% hombres 
y 41,3\% mujeres). Con relación a la renta, el 71,4\% de los participantes gana en promedio hasta tres salarios mínimos. El principal motivo del consumo de proteína del suero de leche fue a la hipertrofia muscular (83,5\%). El uso del suplemento Whey Protein fue indicado, en el 62,4\% de los casos, por amigos, vendedores o por iniciativa propia. Conclusión: Es evidente en este estudio que la búsqueda de un mejor rendimiento físico asociado a los patrones estéticos parece estar impulsando el uso de Whey Protein, sin embargo, es necesario también conocer el riesgo del uso excesivo, especialmente cuando no hay acompañamiento de profesional cualificado ni hay recomendaciones sobre cantidad, tipo y fraccionamiento del suplemento.

Descriptores: proteínas; suplementos dietéticos; consumo de alimentos.

\section{INTRODUÇÃO}

O leite bovino é uma fonte altamente biodisponível de proteína, compreendendo $80 \%$ de caseína e $20 \%$ de soro de leite. O Whey Protein (WP), é o suplemento proteico mais vendido em formato de pó1-3.

A Whey protein é considerada uma das proteínas de maior valor biológico, devido a sua rápida digestibilidade, por possuir um alto teor de aminoácidos tanto essenciais quanto os ramificados, BCAAs, mas principalmente alto teor de leucina, e por estimular a síntese proteica muscular ${ }^{4}$.

Sua ingestão está associada à prática ou não de exercício físico tem mostrado benefícios: favorecem o ganho de força muscular; o alto teor de cálcio favorece a redução da gordura corporal e aumento da densidade óssea mineral ${ }^{5,6}$ também parece apresentar um importante papel no controle da glicemia quando consumido antes de uma refeição ${ }^{7}$, pode causar uma diferença no peso corporal associado à diminuição da massa gorda, diminuição da circunferência abdominal ${ }^{8}$.

A indicação do uso de suplementos nutricionais, como o Whey protein, pode ser realizada por nutricionistas ou médicos especializados, após avaliação nutricional9,10. Porém hoje em dia, essa aquisição tem sido até mesmo por iniciativa própria11,12.

Contudo, segundo Hernandez e Nahas ${ }^{10}$, o consumo excessivo de proteína, ou seja, a ingestão além das recomendações diárias, não proporciona um ganho extra de massa muscular e nem melhora no desempenho. A proteína consumida acima do recomendado pode ser utilizada como fonte de energia e ocasionar um acúmulo de amônia, o que poderia acarretar uma sobrecarga da função renal.

Em função do elevado consumo e dos questionamentos que envolvem o consumo de Whey protein, seja por praticantes de atividade física ou não, esse estudo tem como objetivo avaliar o perfil do consumo de Whey protein em estudantes universitários Porto Alegre, RS.

\section{MATERIAIS E MÉTODOS}

Trata-se de um estudo transversal, no qual a população amostral foi constituída de indivíduos de ambos os gêneros, com mais de 18 anos, que estavam matriculados nos cursos das áreas Biológicas, Naturais e Agrárias da Universidade Federal do Rio Grande do Sul (UFRGS) localizada em Porto Alegre, RS, sendo essas áreas contempladas por sorteio. Os cursos pertencentes a essas áreas são Agronomia, Biotecnologia, Ciências Biológicas, Ciências Biológicas - Ensino à distância, Engenharia Ambiental, Engenharia Cartográfica, Engenharia de Alimentos, Geografia, Geologia, Medicina Veterinária, Química, Zootecnia.

Para a realização da pesquisa foram realizados contatos prévios com as Coordenações de cada curso selecionado. Dessa forma os coordenadores tomaram ciência da realização da proposta do estudo e encaminharam a autorização para a realização do estudo com seus alunos

O tamanho da amostra para o presente estudo foi de 133 universitários dos cursos sorteados, para os quais foram encaminhados o Termo de Consentimento Livre e Esclarecido (TCLE), o link com o questionário da pesquisa sobre o perfil dos consumidores de Whey protein.
O questionário continha questões fechadas e abertas e foi disponibilizado através de um link gerado pelo Survio - software e o instrumento de pesquisa para coleta dos dados foi baseado no questionário semiestruturado, denominado PUSA (Perfil dos Usuários de Suplemento Alimentar), adaptado de Albino, Campos e Martins ${ }^{13}$.

As variáveis que foram avaliadas pelo questionário foram: idade; gênero; condições socioeconômicas, como: renda; dados sobre estilo de vida, como: se era vegetariano e praticante de atividade física. Já as questões referentes ao consumo de Whey protein foram sobre quais os motivos para o uso, quem realizou a indicação para o uso, qual sua dose diária de ingestão, qual a frequência de consumo diária e semanal, qual seu investimento mensal, há quanto tempo realiza o consumo de Whey protein, de que forma é realizado o consumo e se após o uso foi observado algum tipo de alteração.

Esse estudo foi submetido aos Comitês de Pesquisa e Comitê de Ética da UFRGS e somente após a aprovação (CAAE:50954415.0.0000.5347) foi iniciado, seguindo a Resolução 466/2012 do CNS.

Os resultados obtidos foram avaliados de forma categórica, sendo assim os dados foram descritos por valores absolutos e por percentuais. Enquanto que para avaliar a associação entre as variáveis foram realizados o teste Qui-quadrado de Pearson ou Exato de Fischer. Os resultados das análises foram calculados com o nível de significância de 5\% de probabilidade de erro $(p \leq 0,05)$, no programa no software estatístico SPSS, versão 21, 2012.

\section{RESULTADOS}

Observou-se que a faixa etária mais presente dos participantes deste estudo foi de 18 a 28 anos, sendo 82\% (n=109) dos universitários. Por se tratar de uma pesquisa realizada com alunos matriculados em uma universidade verificou-se que a maioria era jovem, os quais ingressaram na instituição logo após completar o Ensino Médio.

Em relação à renda, no presente estudo, 45,1\% $(n=60)$ dos universitários responderam que recebem de um a três salários mínimos (até $R \$ 2.460,00$ reais). Pode-se observar que 91,7\% ( $n=55)$ dos participantes dessa faixa de renda possuem 18 a 28 anos, demonstrando relação positiva significativa $(p<0,001)$. Corroborando assim, que a população com a melhor situação financeira relatada no estudo, de três a nove salários mínimos (de $\mathrm{R} \$ 2.640,00$ até $7.920,00)$, são os participantes de 29 a 38 anos, representando $55,6 \%(n=5)$ da amostra.

Em contrapartida, 26,3\% ( $n=36$ ) do público estudado relatou não ter nenhuma renda, sendo que $97,2 \%(n=35)$ desses estão na faixa etária de 18 a 28 anos. Em relação ao estilo de vida e hábitos alimentares dos universitários que participaram do estudo, apenas 10,5\% $(n=14)$ dos universitários são vegetarianos e fazem uso de Whey protein.

Quanto ao motivo da ingestão de Whey protein (Tabela 1), houve diferença estatística significativa entre a população vegetariana e o motivo do consumo. 
Tabela 1. Fatores relacionados ao consumo em universitários vegetarianos e não vegetarianos que consomem Whey protein da cidade de Porto Alegre, RS, 2016.

\begin{tabular}{|c|c|c|c|}
\hline & \multicolumn{2}{|c|}{ Gênero } & \multirow[b]{2}{*}{$p$} \\
\hline & Feminino & Masculino & \\
\hline Não - vegetarianos & $41,4 \%(n=55)$ & $58,6 \%(n=78)$ & \\
\hline \multirow[t]{3}{*}{ Vegetarianos } & $18,2 \%(10)^{*}$ & $5,1 \%(4)$ & 0,0 \\
\hline & \multicolumn{2}{|c|}{ Vegetarianos } & \\
\hline & $\operatorname{Sim} \%(n=14)$ & Não \% $(n=119)$ & $P$ \\
\hline \multicolumn{4}{|l|}{ Objetivo consumo WP } \\
\hline Aumentar energia & $7,1 \%(1)$ & $15,1 \%(18)$ & 0,689 \\
\hline Perda de Peso & $35,7 \%(5)^{*}$ & $10,1 \%(12)$ & 0,022 \\
\hline Performance atlética & $21,4 \%(3)$ & $26,9 \%(32)$ & 0,906 \\
\hline Deficiências Nutricionais & $50,0 \%(7)^{*}$ & $7,6 \%(9)$ & $<0,001$ \\
\hline Ganho de massa muscular & $57,1 \%(8)$ & $87,4 \%(104)^{*}$ & 0,011 \\
\hline Outros & $07,1 \%(1)$ & $2,5 \%(3)$ & 0,363 \\
\hline \multicolumn{4}{|l|}{ Alteração após consumo WP } \\
\hline Ganho força ou massa muscular & $57,1 \%(8)$ & $76,5 \%(91)$ & 0,213 \\
\hline Perda de peso & $21,4 \%(3)$ & $16,8 \%(20)$ & 0,953 \\
\hline Melhora saúde/maior disposição & $21,4 \%(3)$ & $16 \%(19)$ & 0,889 \\
\hline Nenhuma alteração & $28,6 \%(4)$ & $10,9 \%(13)$ & 0,148 \\
\hline
\end{tabular}

Quando toda a população do estudo foi avaliada, ou seja, não se levando em consideração os gêneros, sobre os motivos do consumo de Whey protein, $83,5 \%(n=111)$ relataram uso por motivos de ganho de massa muscular e 26,3\% ( $n=35)$ para melhorar a performance atlética.

Quando os respondentes foram inquiridos sobre quem indicou o uso de WP, 69,2\% ( $n=54)$ dos homens informaram que adquiriram o produto por iniciativa própria ou por indicação de amigos e lojistas. O nutricionista apareceu em 45,5\% ( $n=25)$ das respostas das mulheres e o educador físico em 32,1\% ( $n=25)$ apareceu das respostas masculinas (Tabela 2).

Quando se avaliou a prática de atividade física e a utilização de Whey protein, observou-se que $97 \%(n=130)$ dos universitários são praticantes de atividade física. Destes, 47,69\% ( $n=62)$ realizam atividade física anaeróbica, sendo a musculação a atividade física que mais apareceu entre as respostas.

Dos universitários que realizam atividade física, a maior parte mencionou realizar exercício físico de uma a quatro vezes na semana, 65,6\% ( $n=86)$, enquanto que $28,6 \%(n=38)$ informaram a prática de atividade física de cinco a seis vezes na semana. Quando relacionado ao gênero não houve diferença estatística significativa (Tabela 2).

Em relação à dose consumida (scoop), 93,2\% ( $n=124)$ dos universitários utilizam até dois scoops de Whey protein (30 gramas)/dia. Enquanto que o consumo diário da maioria dos estudantes consumidores de Whey protein ocorre uma vez/dia, caracterizando o consumo de $88 \%(n=116)$ dos participantes. Desta maneira, conforme se pode observar na Tabela 3, houve diferença estatística significativa quando relacionados dose diária e número de vezes/dia do consumo do suplemento. De acordo com as análises, quem utiliza até dois scoops/dia de Whey protein tende a consumi-lo apenas uma vez durante o dia. Do total, 91,1\% $(n=113)$ dos universitários do estudo se encontram nessa relação $(p=0,001)$.

Quanto ao tempo de utilização de Whey protein, a maioria dos participantes relatou fazer o uso por até 12 meses, 63,15\% ( $n=84)$. Os universitários que relataram utilizar o suplemento por mais de 12 meses foram 30,8\% ( $n=41)$ dos respondentes.

De acordo com a Tabela 3 os consumidores de Whey protein por mais de um ano tendem a consumir cinco ou mais vezes durante a semana $(p=0,005)$. Deste modo, as pessoas que consomem Whey protein por cinco ou mais vezes/semana são aqueles que utilizam o suplemento proteico por mais tempo.
Tabela 2. Atividade física, motivo do consumo, alterações referidas após consumo e indicação do consumo de Whey protein em relação aos gêneros dos universitários da cidade de Porto Alegre, RS, 2016.

\begin{tabular}{|c|c|c|c|}
\hline & Feminino & Masculino & \multirow{2}{*}{$p$} \\
\hline & $41,4 \%(n=55)$ & $58,6 \%(n=78)$ & \\
\hline \multicolumn{4}{|l|}{ Objetivo consumo WP } \\
\hline Aumentar energia & $5,5 \%(3)$ & $20,5 \%(16)^{*}$ & 0,028 \\
\hline Emagrecimento & $18,2 \%(10)$ & $9 \%(7)$ & 0,193 \\
\hline Performance atlética & $10,9 \%(6)$ & $37,2 \%(29)^{*}$ & 0,001 \\
\hline Deficiências nutricionais & $16,4 \%(9)$ & $9 \%(7)$ & 0,308 \\
\hline Ganho de massa muscular & $81,8 \%(45)$ & $85,9 \%(67)$ & 0,694 \\
\hline \multicolumn{4}{|l|}{ Alteração após consumo WP } \\
\hline $\begin{array}{c}\text { Ganho de força ou aumento } \\
\text { massa muscular }\end{array}$ & $67,3 \%(37)$ & $79,5 \%(62)$ & 0,165 \\
\hline Perda de peso & $20 \%(11)$ & $15,4 \%(12)$ & 0,645 \\
\hline Melhora estado de saúde & $16,4 \%(9)$ & $16,7 \%(13)$ & 1,00 \\
\hline Maior disposição & $18,2 \%(10)$ & $15,4 \%(12)$ & 0,849 \\
\hline \multicolumn{4}{|l|}{ Indicação do consumo WP } \\
\hline Educador Físico & $23,6 \%(13)$ & $32,1 \%(25)$ & 0,388 \\
\hline Nutricionista & $45,5 \%(25)$ & $28,2 \%(22)$ & 0,062 \\
\hline Iniciativa própria & $34,5 \%(19)$ & $51,3 \%(40)$ & 0,083 \\
\hline Amigos & $12,7 \%(7)$ & $16,7 \%(13)$ & 0,704 \\
\hline Loja & $3,6 \%(2)$ & $1,3 \%(1)$ & 0,569 \\
\hline Outros & $1,8 \%(1)$ & 0 & 0,414 \\
\hline Atividade física & $94,5 \%(52)$ & $96,2 \%(75)$ & 0,691 \\
\hline \multicolumn{4}{|l|}{ Tipo atividade Física } \\
\hline Nenhum & $1,8 \%(1)$ & $2,6 \%(2)$ & \multirow{4}{*}{0,598} \\
\hline Aeróbico & $16,4 \%(9)$ & $11,5 \%(9)$ & \\
\hline Anaeróbico & $35,4 \%(22)$ & $64,5 \%(40)$ & \\
\hline Aeróbico e anaeróbico & $41,8 \%(23)$ & $34,6 \%(27)$ & \\
\hline \multicolumn{4}{|l|}{ Vezes/ semana Atividade Física } \\
\hline De 1 a 4 vezes/semana & $75,9 \%(41)$ & $58,4 \%(45)$ & \multirow{2}{*}{0,059} \\
\hline 5 ou mais vezes/semana & $24,1 \%(13)$ & $41,6 \%(32)$ & \\
\hline
\end{tabular}

Whey Protein: WP; Teste Qui-quadrado de Pearson ou Exato de Fischer *Significa associação direta, $\mathrm{p} \leq 0,05$.

Tabela 3. Dose consumida e tempo de consumo em relação quantidade do consumo diário e semanal de Whey protein em universitários da cidade de Porto Alegre, RS, 2016

\begin{tabular}{|c|c|c|c|}
\hline & \multicolumn{2}{|c|}{ Dose consumida WP } & \multirow{2}{*}{$p$} \\
\hline & Até 2 scoops/dia & De 3 a 4 scoops/dia & \\
\hline \multicolumn{4}{|l|}{ Vezes/dia WP } \\
\hline $1 \mathrm{vez} / \mathrm{dia}$ & $91,1 \%(113)^{*}$ & $42,9 \%(3)$ & \multirow{3}{*}{0,001} \\
\hline 2 vezes/dia & $8,9 \%(11)$ & $28,6 \%(2)$ & \\
\hline \multirow[t]{3}{*}{3 vezes/dia } & 0 & $28,6 \%(2)$ & \\
\hline & \multicolumn{2}{|c|}{ Tempo de consumo WP } & \multirow{2}{*}{$p$} \\
\hline & Até 12 meses & Mais de 12 meses & \\
\hline \multicolumn{4}{|l|}{ Vezes/semana WP } \\
\hline 1 a 2 vezes/semana & $14,3 \%(12)$ & 0 & \multirow{3}{*}{0,005} \\
\hline 3 a 4 vezes/semana & $46,4 \%(39)$ & $40 \%(16)$ & \\
\hline 5 ou mais vezes/semana & $39,3 \%(33)$ & $60 \%(24)^{*}$ & \\
\hline \multicolumn{4}{|l|}{ Motivos do consumo WP } \\
\hline Performance atlética & $19 \%(16)$ & $42,5 \%(17)^{*}$ & 0,019 \\
\hline Aumentar energia & $9,5 \%(8)$ & $22,5 \%(9)$ & 0,081 \\
\hline Emagrecimento & $14,3 \%(12)$ & $10 \%(4)$ & 0,824 \\
\hline Deficiências nutricionais & $9,5 \%(8)$ & $17,5 \%(7)$ & 0,306 \\
\hline Ganho de massa muscular & $85,7 \%(72)$ & $82,5 \%(33)$ & 0,727 \\
\hline
\end{tabular}

Whey Protein: WP; Teste Qui-quadrado de Pearson ou Exato de Fischer *Significa associação direta, $p \leq 0,05$.

Quanto aos tipos de Whey protein consumidos, a Whey protein isolada foi a mais citada pelos universitários, 34,6\% ( $n=46)$, seguida da concentrada 24,1\% ( $n=32$ ). Quando avaliados em relação ao gênero (Tabela 4) não houve diferença estatística significativa. Em contrapartida 15\% ( $n=20)$ dos universitários que participaram do estudo não souberam informar qual o tipo de Whey protein era consumido. 
Quando questionados sobre quantas vezes/semana os participantes consumiam Whey protein, a maioria, 45\% $(n=60)$ dos universitários, afirmaram consumir o produto de três a quatro vezes/semana e 33,1\% $(n=44)$ de cinco ou mais vezes/semana. Quando se compara o consumo de Whey protein entre os gêneros, pode-se perceber, na Tabela 4, que houve diferença estatística significativa.

É possível observar na Tabela 5 que os universitários que perceberam alteração após consumo de WP, no caso, ganho de força e massa muscular, 40,8\% (40), tendem a realizar atividade física cinco vezes ou mais durante a semana $(p=0,013)$. Quem não relatou ter percebido ganho de força e massa muscular após o uso de WP, 84,8\% ( $n=28)$, tende a realizar atividade física de uma a quatro vezes/semana.

E relação a alterações percebidas após consumo de Whey protein, $74,4 \%$ ( $n=99$ ) dos acadêmicos perceberam aumento de força e ganho de massa muscular. De forma global, 22,6\% $(n=30)$ dos respondentes utilizam Whey protein para ter maior disposição.

Quando os universitários foram avaliados em relação as alterações após consumo de Whey protein, como perda de peso e melhora do estado de saúde, não foram observadas diferença estatística significativa (Tabela 5).

Tabela 4. Fatores relacionados ao consumo da proteína do soro do leite em relação aos gêneros em universitários da cidade de Porto Alegre, RS, 2016.

\begin{tabular}{|c|c|c|c|}
\hline \multirow{2}{*}{ Fatores } & Feminino & Masculino & \multirow{2}{*}{$p$} \\
\hline & $41,4 \%(n=55)$ & $58,6 \%(n=78)$ & \\
\hline \multicolumn{4}{|l|}{ Tipo de WP } \\
\hline Puro (WPI ou WPC ou WPI) & $69,1 \%(38)$ & $57,7 \%(7)$ & \multirow{3}{*}{0,359} \\
\hline Blend(mistura de tipos) & $18,2 \%(10)$ & $21,8 \%(17)$ & \\
\hline Não sei & $12,7 \%(7)$ & $20,5 \%(16)$ & \\
\hline \multicolumn{4}{|l|}{ Dose consumida WP } \\
\hline Até 2 scoops/dia & $96,4 \%(53)$ & $91 \%(61)$ & \multirow{2}{*}{0,368} \\
\hline De 3 a 4 scoops/dia & $1,8 \%(1)$ & $7,7 \%(6)$ & \\
\hline \multicolumn{4}{|l|}{ Vezes/dia WP } \\
\hline 1 vez /dia & $90,9 \%(50)$ & $87,2 \%(68)$ & \multirow{3}{*}{0,693} \\
\hline 2 vezes/dia & $9,1 \%(5)$ & $10,3 \%(8)$ & \\
\hline 3 vezes/dia & 0 & $2,6 \%(2)$ & \\
\hline \multicolumn{4}{|l|}{ Vezes/semana WP } \\
\hline 1 a 2 vezes/semana & $21,8 \%(12)^{*}$ & $2,6 \%(2)$ & \multirow{3}{*}{0,001} \\
\hline 3 a 4 vezes/semana & $47,3 \%(26)$ & $43,6 \%(34)$ & \\
\hline 5 ou mais vezes/semana & $30,9 \%(17)$ & $53,8 \%(42)^{*}$ & \\
\hline \multicolumn{4}{|l|}{ Tempo de consumo WP } \\
\hline Até 12 meses & $74,5 \%(41)$ & $55,8 \%(43)$ & \multirow{3}{*}{0,066} \\
\hline Mais de 12 meses & $20 \%(11)$ & $37,9 \%(29)$ & \\
\hline Outros & $5,5 \%(3)$ & $6,5 \%(5)$ & \\
\hline
\end{tabular}

Whey Protein:WP;WPI:WP Isolado; WPC:WP Concentrado; WPH:WP Hidrolisado; Teste Qui-quadrado de Pearson ou Exato de Fischer *Significa associação direta, $p \leq 0,05$.
Em relação às alterações após consumo de Whey protein, na Tabela 5 pode-se verificar que $93,2 \%$ ( $n=55$ ) dos participantes que fizeram o uso de Whey protein sem nenhum acompanhamento por um profissional especializado tendem a não conseguir perder peso após o consumo $(p=0,008)$

Em contrapartida, 30,5\% ( $n=18)$ dos universitários que referiram como alteração após consumo de Whey protein melhora no estado de saúde, fizeram o uso de Whey protein por iniciativa própria ou indicação de amigos ou até mesmo por sugestão de vendedores de lojas de suplementos, apresentando diferença estatística significativa $(p<0,001)$ (Tabela 5).

Quando questionados sobre o investimento mensal 23,3\% $(n=31)$ dos usuários de Whey protein mencionaram que o gasto é de $\mathrm{R} \$ 100,00$ a 150,00 reais por mês; $21,8 \%(n=29)$ gastam em torno de $R \$ 75,00$ a 100,00 reais durante o mês.

\section{DISCUSSÃO}

Lollo e Tavares ${ }^{14}$ também encontraram maior número de consumidores de suplementos na faixa etária entre 17 e 34 anos. De acordo com Aranha et al. ${ }^{15}$, o consumo de suplementos em pessoas nessa faixa etária pode estar relacionado ao desejo de aparentar uma melhor forma física estimulados pelos padrões estéticos ditados pela sociedade, e à falta de tempo para alimentação adequada aliada a necessidade de se atingir rapidamente os resultados.

Em relação à renda dos participantes, por serem alunos de uma universidade federal, a qual possui uma demanda de carga horária que envolve turno integral, os estudantes não consigam realizar estágios ou possuir emprego, obtendo assim apenas um auxílio familiar para custear suas despesas.

Dentre os consumidores vegetarianos, existe a recomendação de suplementos proteicos como uma estratégia para evitar deficiências proteicas que podem surgir através da eliminação do consumo da proteína animal. Todavia, nem todos os casos necessitam dessa suplementação, pois através de uma alimentação equilibrada é possível se ter uma dieta saudável e que disponibilize todos aminoácidos necessários diariamente ${ }^{16}$.

Campos et al. ${ }^{17}$ ao avaliar publicações sobre o a dieta vegetariana encontrou relação com o gênero, demonstrando predomínio das muIheres se tornarem mais vegetarianas em relação aos homens.

O maior consumo de suplementos alimentares pelos homens em comparação com as mulheres, segundo Ronsen et al. ${ }^{18}$, pode ser atribuída ao fato que os homens ingerem os suplementos alimentares de uma forma regular para manutenção de seus propósitos e o gênero feminino consome os suplementos alimentares de uma forma ocasional, apenas para alcançar seus resultados.

Tabela 5. Alterações observadas após o uso de Whey protein pelos universitários da cidade de Porto Alegre, RS, 2016.

\begin{tabular}{|c|c|c|c|c|c|c|c|c|c|}
\hline & \multicolumn{9}{|c|}{ Alteração após consumo WP } \\
\hline & \multicolumn{2}{|c|}{$\begin{array}{c}\text { Ganho de força/Aumento } \\
\text { massa muscular }\end{array}$} & \multirow{2}{*}{$p$} & \multicolumn{2}{|c|}{ Perda de peso } & \multirow{2}{*}{$p$} & \multicolumn{2}{|c|}{ Melhora estado de saúde } & \multirow{2}{*}{$p$} \\
\hline & $\begin{array}{c}\operatorname{Sim} \\
\%(n=98)\end{array}$ & $\begin{array}{c}\text { Não } \\
\%(n=33)\end{array}$ & & 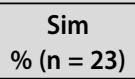 & $\begin{array}{c}\text { Não } \\
\%(n=108)\end{array}$ & & $\begin{array}{c}\operatorname{Sim} \\
\%(n=10)\end{array}$ & $\begin{array}{c}\text { Não } \\
\%(n=66)\end{array}$ & \\
\hline \multicolumn{10}{|c|}{ Vezes/semana Atividade Física } \\
\hline 1 a 4 & $59,2 \%(58)$ & $84,8 \%(28)$ & \multirow{2}{*}{0,013} & $73,9 \%(17)$ & $63,9 \% 69)$ & \multirow{2}{*}{0,498} & $13,6 \%(3)$ & $9,9 \%(11)$ & \multirow{2}{*}{0,645} \\
\hline 5 ou mais & $40,8 \%(40)^{*}$ & $15,2 \%(5)$ & & $26,1 \%(6)$ & $36,1 \%(39)$ & & $36,4 \%(8)$ & $46,8 \%(52)$ & \\
\hline Educador físico & $76,3 \%(29)$ & $23,7 \%(9)$ & 0,925 & $23,7 \%(9)$ & $76,3 \%(29)$ & 0,328 & $13,2 \%(5)$ & $86,8 \%(33)$ & 0,685 \\
\hline Nutricionista & $80,9 \%(38)$ & $19,1 \%(9)$ & 0,296 & $21,3 \%(10)$ & $78,7 \%(37)$ & 0,510 & $12,8 \%(6)$ & $87,2 \%(41)$ & 0,534 \\
\hline Iniciativa Própria & $78 \%(46)$ & $22 \%(13)$ & 0,527 & $6,8 \%(4)$ & $93,2 \%(55)^{*}$ & 0,008 & $30,5 \%(18)^{*}$ & $69,5 \%(41)$ & $<0,001$ \\
\hline Amigos & $75 \%(15)$ & $25 \%(5)$ & 0,999 & 0 & $110 \%(20)$ & 0,058 & $30 \%(6)$ & $70 \%(14)$ & 0,152 \\
\hline
\end{tabular}


Pereira ${ }^{12}$ encontrou em seu estudo que 45\% ( $n=34$ ) dos usuários fazem o uso de suplementos sem nenhuma orientação ou prescrição por um profissional especializado e iniciam o uso através de iniciativa própria ou influenciados por amigos. Tais eventos se mostram preocupantes, tendo em vista que na maioria da população estudada a prescrição dos suplementos alimentares está sendo feita por pessoas sem formação apropriada, podendo acarretar em um consumo excessivo de proteínas e de calorias, gerando aumento do percentual de gordura corporal ${ }^{19}$.

A recomendação de proteína para adultos jovens sedentários é de $0,8 \mathrm{~g}$ de proteína/kg/dia e para atletas que visam à hipertrofia muscular teriam suas necessidades atingidas com o consumo de no máximo 1,8g/ $\mathrm{kg} / \mathrm{dia}^{10}$. Segundo Haraguchi et al. ${ }^{5}$, o excesso de ingestão de proteínas pode induzir a patologias hepáticas e renais (ingestão de proteína acima de $2 \mathrm{~g} / \mathrm{kg}$ de peso/dia).

Estudos demonstram que após o treino ocorre uma queda na concentração de aminoácidos intracelulares e nos músculos. Dessa forma, a ingestão de proteínas ou aminoácidos imediatamente após o exercício pode promover a síntese de proteínas nos músculos, sendo assim o Whey protein, devido à sua rápida absorção, promoveria a recuperação após esforço ${ }^{20}$.

Duarte et al. ${ }^{21}$ demonstraram em seu estudo que a maioria dos consumidores de suplementos alimentares realizam o consumo diariamente. Apesar de muitos estudos demonstrarem possíveis mudanças consideradas positivas na reposição dos estoques energéticos, o uso excessivo desses produtos pode atuar de forma contraditória em algumas situações, trazendo efeitos colaterais e tóxicos ao organismo quando usado com imprudência22.

A busca por um melhor desempenho físico associado a padrões estéticos parecem estar impulsionando o uso de Whey protein, contudo se faz necessário conhecer também o risco de seu uso exacerbado, principalmente quando o profissional qualificado não realiza o acompanhamento do paciente, nem tampouco recomendou quantidade, tipo e fracionamento do consumo. Merece ser ressaltado que hábitos alimentares saudáveis associados à atividade física orientada serão sempre opções mais promissoras.

É importante frisar a escassez de estudos que investiguem o perfil de consumidores de Whey protein no Rio Grande do Sul e no Brasil e salientar que os estudos existentes contêm apenas análises descritivas. Sendo assim, se torna complexo comparar diferentes amostras, grupos, propostas de estudos e resultados sobre esse tipo de consumo.

\section{CONCLUSÃO}

Os universitários avaliados possuem renda de um a Três salários mínimos e apresentam faixa etária entre 18 a 28 anos.

São minoritariamente vegetarianos e consomem o suplemento visando prevenir deficiências nutricionais e os não vegetarianos utilizam Whey protein para ganho de massa muscular.

Em relação ao consumo diário, o uso é de até dois scoops/dia de Whey protein, associado a frequência de uso do produto uma vez/dia. Quando o tempo de consumo foi superior a 12 meses estava associado à ingestão de cinco ou mais vezes/semana. Além disso, os homens são os consumidores dessa maior quantidade, e as mulheres apenas uma a duas vezes/semana.

Os universitários que não observaram perda de peso como alteração após consumo, referiram à aquisição e uso de Whey protein por iniciativa própria.

Todos os autores declararam não haver qualquer potencial conflito de interesses referente a este artigo.

CONTRIBUIÇÕES DOS AUTORES: Cada autor contribuiu individual e significativamente para o desenvolvimento do manuscrito. JOS (0000-0002-0659-671X)* foi a responsável pela execução de todo o trabalho e da escrita. VRK (0000-0002-6737-1039)* participou da concepção do projeto e auxiliou na redação e revisão crítica. VRO (0000-0001-6029-2525)* foi a coordenadora da pesquisa, auxiliou na redação e na revisão crítica do manuscrito. *ORCID (Open Researcher and Contributor ID).

\section{REFERÊNCIAS}

1. Pereira RF, Lajolo FM, Hirschbruch MD. Consumo de suplementos por alunos de academias de ginástica em São Paulo. Rev Nutr. 2003;16(3):265-72.

2. Araújo LR, Andreolo J, Silva MS. Utilização de suplemento alimentar e anabolizante por praticantes de musculação nas academias de Goiânia - GO. Rev Bras Ciênc Mov. 2002;10(3):13-18.

3. Hallak A, Fabrinl S, Peluzio MC. Avaliação do consumo de suplementos nutricionais em academias da zona Sul de Belo Horizonte, MG, Brasil. Rev Bras Nut Esportiva. 2007;1 (2):55-60.

4. Devries MC, Phillps SM. Supplemental protein in support of muscle mass and health: advantage whey. J Food Sci. 2015;80(1):A8-A15

5. Haraguchi FK, Abreu WC, Paula H. Proteínas do soro do leite: composição, propriedades nutricionais, aplicações no esporte e benefícios para a saúde humana. Rev Nutr. 2006;19(4):479:88.

6. Carrilho LH. Benefícios da utilização da proteína do soro de leite WP. Rev Bras Nut Esportiva. 2013;7(40):195-203.

7. Akhavan T, Luhovyy BL, Brown PH, Cho CE, Anderson GH. Effect of premeal consumption of Whey Protein and its hydrolysate on food intake and postmeal glycemia and insulin responses in young adults. Am J Clin Nutr. 2010;91(4):966-75.

8. Baer DJ, Stote KS, Paul DR, Harris GH, Rumpler WV, Clevidence BA. Whey Protein but not soy protein supplementation alters body weight and composition in free-living overweight and obese adults. J Nutr. 2011 Aug;141(8):1489-94

9. BRASIL. Resolução CFN № 390/2006. Regulamenta a prescrição dietética de suplementos nutricionais pelo nutricionista e dá outras providências. Brasília, DF: Conselho Federal de Nutricionistas; 2006.

10. Hernandez AJ, Nahas RM. Modificações dietéticas, reposição hídrica suplementos alimentares e drogas: comprovação de ação ergogênica e potenciais riscos para a saúde. Suplemento. Rev Bras Med Esporte. 2009;15(3):3-12.

11. Cantori AM, Sordi MF, Navarro AC. Conhecimento sobre ingestão de suplementos por frequentadores de academias em duas cidades diferentes no Sul do Brasil. Rev Bras Nut Esportiva. 2009;(3)15:172-81.
12. Pereira LP. Utilização de recursos ergogênicos nutricionais e/ou farmacológicos em uma academia da cidade de Barra do Piraí, RJ. Rev Bras Nut Esportiva. 2014;8(43):58-64.

13. Albino CS, Campos PE, Martins RL. Avaliação do consumo de suplementos nutricionais em academias de Lages-SC. EF Deportes.com Buenos Aires. 2009;14(134). Disponível em: http://www.efdeportes. com/efd134/consumo-de-suplementos-nutricionais-em-academias.htm. [acesso em 2016 abr 23]

14. Lollo PCB, Tavares MCG. Consumidores de suplementos alimentares nas academias de Campinas, SP, Brasil. In: Congresso Internacional de Educação Física. Foz do Iguaçu, PR-Brasil; 2004.

15. Aranha MCG, Costa MA, Moreira JKR, Rocha RM, Pinheiro JMA. O uso de suplementos WP e BCAA em adultos praticantes de musculação em uma academia de Belém, PA. FIEP BULLETIN. 2012;82:1:7.

16. Nieman D. Physical fitness and vegetarian diets: is there a relation? Am J Clin Nutr. 1999;70(3 Suppl):570S-5S.

17. Campos AAC, Madruga LB, Santos MR, Cheavegagatti D. Regime alimentar vegetariano: revisão de literatura. Ciênc Consciên. 2010(2). Disponível em http://revista.ulbrajp.edu.br/ojs/index.php/ciencia/ article/view/482. [acesso em 2016 mar 21]

18. Ronsen O, Sundgot BJ, Maehum S. Supplement use in nutritional habits in Norwegian elite athletes. Scand J Med Sci Sports. 1999;9(1):28-35.

19. Gomes GS, Degiovanni GC, Garlipp MR, Chiarello PG, Jordão Jr AA. Caracterização do consumo de suplementos nutricionais em praticantes de atividade física em academias. Medicina (Ribeirão Preto). 2008:41(3):327-31.

20. Pacheco MTB, Bighetti E, Antônio M, Carvalho JE, Rosaneli CF, Sgarbieri VC. Efeito de um hidrolisado de proteínas de soro de leite e de seus peptídeos na proteção de lesões ulcerativas da mucosa gástrica de ratos. Rev Nut. 2006;19(1):47-55

21. Duarte PSF, Zaninelo MO, Pelizer LH, Santos CM, Neiva CM. Aspectos gerais e indicadores estatísticos sobre o consumo de suplementos nutricionais em academias de ginástica. Rev Nutr Pauta. 2007;15(82):27-31

22. Matos JB, Liberali R. O uso de suplementos nutricionais entre atletas que participaram da segunda travessia da lagoa do Peri de 3.000m. Rev Bras Nut Esportiva. 2008;2(10):185-97. 